\title{
"Na saúde, tivemos vários momentos muito difíceis, mas conseguimos dar a volta por cima"
}

\author{
"We were often going through hard times in the sphere of health \\ system, but we could bounce back after each one"
}

\section{"En el ámbito del sistema de salud tuvimos varios periodos bastante dificiles, pero siempre nos erguimos otra vez"}

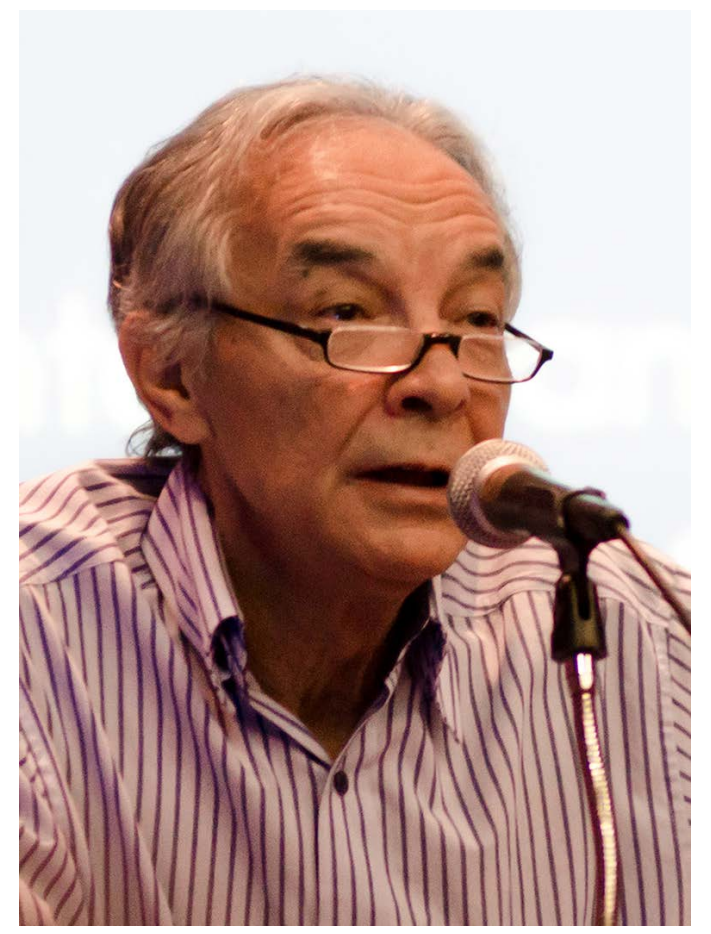

Para marcar os 30 anos da histórica $8^{\mathrm{a}}$ Conferência Nacional de Saúde publicamos, na estreia desta seção, uma entrevista com Jairnilson Paim, pesquisador e professor titular do Instituto de Saúde Coletiva da Universidade Federal da Bahia (ISC/Ufba).

jairnilson@ufba.br

Palavras chave: Sistema Único de Saúde; Movimento da Reforma Sanitária; Políticas Públicas de Saúde; regionalização; acesso à informação.

Keywords: Unified Health System; Health Care Reform; Public Health Policy; Regional health planning; access to information.

Palabras claves: Sistema Único de Salud; Reforma de la Atención de Salud; políticas públicas de salud; regionalización; acceso a la información.

Entrevistadores: Ana Luiza Braz Pavão, André Bezerra, Christovam Barcellos, Frederico Tomás Azevedo, Igor Pinto Sacramento, Lidiane dos Santos Carvalho, Rosany Bochner, Rodrigo Murtinho.

Fotografia: Raquel Portugal

Licença CC BY-NC atribuição não comercial. Com essa licença é permitido acessar, baixar (download), copiar, imprimir, compartilhar, reutilizar e distribuir os artigos, desde que para uso não comercial e com a citação da fonte, conferindo os devidos créditos de autoria e menção à Reciis. Nesses casos, nenhuma permissão é necessária por parte dos autores ou dos editores. 
Reciis: O senhor identificou o processo da Reforma Sanitária Brasileira (RSB) com o conceito de "revolução passiva"", em que prevalece a lógica do "conservar-mudando". Três décadas depois, o processo da RSB permanece nesses moldes? Que elementos a tornariam uma "reforma social geral" ou uma "revolução no modo de vida" como anunciou seu projeto original?

Jairnilson Paim: Creio que essa categoria de "revolução passiva" continua vigente para examinar a Reforma. Eu acrescentaria ainda que - não como algo externo à reforma, ou seja, a da sociedade brasileira - a própria Reforma Sanitária Brasileira enquanto um processo, que tem idas e vindas, avanços e recuos, passou a ter a sua "revolução passiva" específica. Ou seja, no interior do processo da Reforma Sanitária, não por um determinante externo, mas dentro dela própria, há momentos que são construídos por sujeitos que fazem avançá-la, mas também no interior desse mesmo processo há sujeitos que fazem com que ela fique estagnada ou mesmo retroceda.

Então eu diria que o conceito gramsciano de "revolução passiva" está vigente não só para entender a sociedade brasileira, como também para explicar as próprias idas e vindas específicas da Reforma Sanitária no Brasil enquanto processo. No meu livro sobre a Reforma Sanitária ${ }^{2}$ chego a chamar a atenção para o fato de serem vários os momentos da Reforma que podem ser examinados: o momento da ideia, o momento da proposta, o momento do movimento, do projeto e do processo. Quer dizer, entendendo a Reforma como um processo, não necessariamente ela vai ter as mesmas dimensões ou as mesmas características da sua ideia original, da sua proposta ou do seu projeto, mas são as circunstâncias, as situações conjunturais que vão dar o elemento mais progressista ou regressivo dessa reforma. Então eu vejo que a "revolução do modo de vida" ou a "reforma total" - não são categorias gramscianas, são da Agnes Heller³ , quando ela estuda diferentes tipos de práxis dentro de uma sociedade -, essa reforma geral não ocorreu. Porque é aquilo que Arouca chamava a atenção sobre a reforma sanitária verdadeira incluir uma totalidade de mudanças - a reforma sanitária, a reforma agrária, a reforma universitária, a reforma tributária, a reforma urbana -, esse conjunto de reformas é que daria um caráter de "reforma geral" e de "revolução do modo de vida". Portanto, a Reforma Sanitária, ao cuidar das pessoas no seu cotidiano - questões de gênero, da cultura, psicológica e várias outras dimensões que não estavam restritas à produção econômica - traz maneiras diferentes de você "andar a vida", outra categoria muito adotada na saúde coletiva, "modos de andar a vida", do Canguilhem4.

A "revolução do modo de vida", segundo Agnes Heller, ocorre quando você consegue não apenas tomar o poder do Estado, não apenas fazer reformas setoriais, mas quando a vida das pessoas se modifica. Ela explica isso dizendo que não existem experiências concretas - quando ela pesquisou para ilustrar a "revolução do modo de vida" - porque geralmente as revoluções foram até a tomada do poder e a implantação de determinada forma de organização da sociedade, mas não mudaram a vida das pessoas. Então ela disse que talvez as experiências da humanidade que mais se aproximariam da ideia de "revolução no modo de vida" teriam sido o Iluminismo e o Cristianismo. Porque as pessoas, de alguma maneira, modificaram o seu cotidiano a partir do Iluminismo, a partir da ideia da razão, e no Cristianismo quando, passados tantos séculos depois de Cristo, as pessoas ainda falam dessas coisas, ainda vão à igreja. Enfim, então eu acho que essa "revolução no modo de vida" não era uma prescrição da Reforma Sanitária, mas estava nas entrelinhas ou no horizonte, porque ela não significava apenas reorganizar o serviço de saúde, tinha a ver com os "modos de andar a vida" das pessoas.

i Conceito desenvolvido por Gramsci em sua obra I/ Resorgimento, a partir do que o filósofo Vicenzo Cuoco havia cunhado no início do século XIX. No Brasil, foi publicada com o título Risorgimento italiano (caderno 19). ${ }^{1}$ 
Reciis: Em seu editorial sobre o futuro do SUS5, publicado em 2012, na revista Cadernos de Saúde Pública, o senhor fala em "sustentabilidade econômica" e "sustentabilidade política". Sobre a primeira, menciona que "se encontra ameaçada" e cita o problema do subfinanciamento do setor saúde. Sobre a segunda, pondera que "caberia analisar quais forças políticas e sociais defendem efetivamente o SUS e quais se aproveitam das suas fragilidades para ampliar a mercantilização e a privatização, diante das ambiguidades e omissões da regulação estatal". Na perspectiva atual, passados quatro anos, na sua opinião, quais foram as mudanças significativas na conjuntura econômica e política no que diz respeito ao Sistema Único de Saúde?

Jairnilson Paim: Eu estava muito preocupado em 2012, porque era praticamente o início de um governo que teria a condição de dar passos importantes em relação ao SUS, e, no entanto, ele estava de alguma maneira subordinado a um debate entre financiamento e gestão. Um problema muito sério, decidir se era financiamento ou gestão, como se fossem coisas contraditórias. Então, isso estava muito no discurso tanto da Presidente quanto do Ministro da Saúde. E nesse editorial - como pediram para eu escrever sobre o futuro do SUS - eu dizia que o futuro do SUS depende do que se faz hoje. E o que estava se fazendo naquela época já anunciava que não ia ser coisa boa, independentemente da crise econômica de 2008 e da crise política que nós estamos vivenciando no momento. Quer dizer, os passos que estavam sendo dados, por exemplo, em determinadas relações com as grandes empresas vinculadas a planos de saúde, que se reuniam de maneira meio clandestina com o Planalto. Ou com certos dirigentes de hospitais privados no Brasil, midiáticos, porque eles estão toda hora na mídia, em contato direto com a Presidência da República. Isso não sinalizava coisas boas para o SUS, isso ainda do ponto de vista de articulações. E quando se via as ações que estavam sendo feitas pelo Executivo em aliança com o Legislativo para impedir que o Saúde + 10 avançasse, quer dizer, o próprio governo já estava, considerando o ponto de vista do Executivo e do Legislativo, inviabilizando a sustentabilidade econômica do SUS. Então é por isso que o editorial traz essa questão de que esse subfinanciamento, que já era crônico, estava sofrendo muito mais ameaças naquele momento, configurando um mau presságio para o SUS. Por outro lado, se não conseguirmos ampliar as nossas bases de sustentação política - os sindicatos, os partidos e certos movimentos em defesa do SUS - ele vai ficar restrito a alguns intelectuais ou algumas instituições, como a Fiocruz, institutos de saúde coletiva, universidades de um modo geral, mas isso é insuficiente para poder manter um projeto da natureza do SUS. Então, esse é um grande desafio para nós: não conseguimos, ao longo desses 40 anos, desde o início do movimento sanitário, considerando o Cebes [Centro Brasileiro de Estudos de Saúde] como uma referência, ampliar as bases de sustentação política para a reforma. Tivemos ganhos? Tivemos. Mas sujeitos coletivos, você tem Conass [Conselho Nacional de Secretários de Saúde], você tem Conasems [Conselho Nacional de Secretarias Municipais de Saúde], você tem AbrES [Associação Brasileira de Economia da Saúde], você tem Abrasco [Associação Brasileira de Saúde Coletiva] e outros, além do Cebes. Mas um projeto da natureza do SUS implica uma reforma democrática do Estado, e mudança de valores da sociedade. Por isso, o Arouca falava de projeto civilizatório. Esses recursos que temos são muito escassos para poder lidar com tanta ousadia e generosidade do projeto de Reforma Sanitária. 
Reciis: O SUS, inicialmente concebido como um sistema de saúde para todos, cada vez mais tem sido associado à parcela menos favorecida da população ("SUS para pobres"). Além disso, temos no Brasil um sistema de saúde com grande participação do setor privado (saúde suplementar). Na sua opinião, considerando a atual conjuntura política e suas incertezas, quais são as ameaças e os desafios para a manutenção do SUS e da saúde como direito?

Jairnilson Paim: Me desculpem pelo trocadilho, mas temos muito a temer, porque o que se coloca não é nada muito favorável em relação ao desenvolvimento do SUS. Mas para além da temeridade, de novo um trocadilho, de mau gosto, nós temos a história, e acho que isso é importante a gente retomar. O SUS já teve grandes ameaças em outros momentos e nem por isso acabou, ainda que tenha sido desfigurado. Mas só para lembrar um pouco, logo que a Constituição cidadã estabeleceu a proposta do SUS, o governo federal deveria encaminhar o projeto de lei, a chamada Lei Orgânica da Saúde, em 18o dias. Não o fez! Teve o ano tumultuado de 1989, que resultou na eleição do presidente Collor, e todo mundo imaginava que aquele recém-nascido que era o SUS ia acabar, e não acabou. Ninguém imaginava que se conseguiria uma lei orgânica da saúde no ano de 1990, e saiu. Houve vários vetos, tudo o que dizia respeito à participação da comunidade e a repasse de recurso ou financiamento o presidente vetou, e se conseguiu reconstruir uma articulação a ponto de em 28 de dezembro de 1990 sair a Lei 8.142, que garante os conselhos, garante as conferências, garante a existência de planos de saúde, de relatório de gestão e de passagens de recursos, mesmo que os repasses ainda não tivessem sendo realizados. Para quem está vivendo essa crise de hoje, tem que se lembrar do que foi naquela época, isso em 1990. O mesmo governo que fazia essas duas leis, no início de 1991, logo no dia 7 de janeiro, baixava uma NOB, a Norma Operacional Básica 01/91, quase que desqualificando e descontruindo tudo o que tinha sido aprovado nas leis anteriores, na 8.080/90 e na 8.142/9o, , trazendo para o sistema de saúde toda a lógica do setor privado que é do pagamento por procedimento etc. Ainda assim, o SUS andou. Em 1993, saiu um documento do governo federal, a chamada NOB 93, talvez vocês se recordem que o título do documento era "a ousadia de cumprir e fazer cumprir a lei”. Quer dizer que país especial é o nosso, que sai um documento oficial do Ministério da Saúde com um título de "ousadia de cumprir e fazer cumprir a lei"? Se esse documento fosse traduzido para outro país, ninguém entenderia como é que num país como o nosso para cumprir a lei tem que ter ousadia. E esse foi um documento de referência, o SUS teve avanços a partir da referência da NOB 93, entendeu? Era um período em que se debatia se a Constituição poderia ser reiterada em determinados aspectos ou não. $\mathrm{E}$ alguém já queria tirar da saúde, direito de todos, dever do Estado na Constituição, dizendo nos termos da lei, ou seja, desconstitucionalizando a ideia de saúde como um direito. E nós conseguimos vencer. Então, temos derrotas sim, mas quem vai estudar a história do sistema vê: vencemos várias crises e, ainda que o sistema não seja aquele que foi projetado, está aí, não é? Quer dizer, você cobrir 200 milhões de habitantes, mesmo que você desconte os que usam menos o SUS; então, que sejam 150 milhões, isso não é pouca coisa. Essas são as ponderações que a gente faz aqui. Eu penso que estamos vivendo um momento difícil, todos temos preocupações, preocupações até muito graves. Mas não é questão de esperança, eu admito que a gente tem que ter o pessimismo da razão, mas tem que ir examinando a história e a práxis e ver que as coisas podem avançar. Eu vou concluir essa resposta dizendo que, sem mencionar muitos partidos, até em partidos que hoje têm sido, por causa do impeachment, considerados de direita, mesmo em partidos considerados de direita hoje, temos gente que defende o SUS. Quer dizer, não vai ser a proposta que os chamados "históricos do SUS" defendem. Como também o PT não defendeu, não é?! Também o PC do B não o fez; e tiveram chance de fazer. 
Reciis: Em artigo publicado em 2000, o professor Valdir de Castro Oliveira ${ }^{6}$ apontou a mídia, já naquele momento, como principal responsável pela conformação de um consenso negativo sobre o Sistema Único de Saúde. Considerando a crescente influência na vida política brasileira, como o senhor avalia hoje o papel da mídia na construção dos valores e sentidos que permeiam as narrativas sobre o SUS?

Jairnilson Paim: Eu não conheço e não estudo a mídia como vocês fazem. Então, a minha resposta vai ter um pouco de senso comum e um pouco de reflexão sobre a minha experiência de vida, daí vocês vão relativizar um pouco a resposta que vou dar para vocês. Eu tenho uma ideia de que a mídia está muito ligada ao projeto mercantilista, isso eu não tenho dúvida. Boa parte da mídia não tem nada a ver com o projeto democrático que está na Constituição, também não tem muito a ver com o projeto que nós chamamos de racionalizador. Mas o que sinto com mais força é a nossa dificuldade de fazer com que, na chamada ponta do sistema, as pessoas sejam bem acolhidas, respeitadas, e que seus problemas e necessidades sejam atendidos. Por mais que melhoremos a mídia, por mais que tenhamos uma mídia parceira, se nós não conseguirmos fazer com que as pessoas sejam atendidas com qualidade, com respeito, com dignidade, não adianta a gente avançar tanto e sofisticar determinadas maneiras de passar mensagens. Vai soar como propaganda enganosa, desculpe um pouco a expressão. Eu acho que o nosso grande desafio é fazer com que a Reforma Sanitária Brasileira chegue na ponta do sistema, e esses valores que nós estamos discutindo aqui possam ser expressos na redefinição dos processos de trabalho, não é?! Quer dizer, na hora em que se está prestando cuidado é que a gente tem como desconstruir determinadas imagens que são desfavoráveis ao SUS. É mostrando que o sistema pode funcionar. Um exemplo que vale ser mencionado é de uma jornalista que me entrevistou recentemente. Depois de fazer perguntas bem insinuantes de que o SUS não funcionava, com depoimento pessoal espontâneo próprio ela mostrou que a mãe era muito bem atendida no Sistema Único de Saúde, em um município em que praticamente 100\% da população daquela capital brasileira tem atenção básica garantida. Então, eu acho importante você considerar a mídia, acioná-la. Não é a comunicação, o agir comunicativo e todas essas invenções, mas sim o melhor aprendizado do sistema, especialmente na ponta, porque o avanço da gestão, o avanço da descentralização, da participação social, tudo isso tem muita relevância para os que pensam saúde coletiva, para os que estudam, para os que pesquisam, mas é abstração para as pessoas. Financiamento, gestão, organização, infraestrutura são abstrações para quem vai buscar o cuidado. Quem vai buscar o cuidado quer atenção, quer cuidado, e se nós não conseguirmos, até por causa das questões administrativas, organizativas, financeiras, de infraestrutura, viabilizar isso, não tem comunicação que dê conta, não vai fazer milagre. Se ela encontrasse uma coisa diferente do que a mídia fala, ela ia começar a duvidar, por que não?! 
Reciis: Em seu artigo intitulado 'A Constituição Cidadã e os 25 anos do Sistema Único de Saúde (SUS) ${ }^{\prime 7}$, o senhor salienta que "Uma atenção especial paraa pluralidadede vozes numa sociedade democrática permitiria constituir sujeitos políticos individuais e coletivos que questionem a subversão dos direitos sociais, as iniquidades em saúde e as relações de subordinações". Nesse aspecto, como a Lei de Acesso à Informação, como direito fundamental, pode influenciar/ direcionar (ou não) a participação popular nas ações do SUS?

Jairnilson Paim: Eu reconheço que a Lei de Acesso é uma lei fundamental. Mas, você tem que ter a disponibilidade do duplo acesso, você também tem que ter uma maneira de dialogar com as pessoas do ponto de vista da organização. Eu acompanhei com muito interesse os movimentos de junho de 2013, e senti muito quando esses movimentos, aparentemente espontâneos, não se estruturaram em organizações. Não precisam necessariamente ser organizações partidárias, o Cebes pode ser um bom exemplo. A tendência é de que esse acesso à informação ou esse acesso ao conhecimento pare aí. A ideia de você estar progressivamente preocupado em constituir novos sujeitos é uma ideia que vai no sentido contrário ao daquela justificativa que muitas vezes nós nos fazemos de que as condições não estão dadas. Quer dizer, tem um grande pensador latino-americano, professor Mario Testa ${ }^{8}$, que diz que desde pequenininho, nos domingos as famílias se reuniam, e seus tios, jogando, examinavam o contexto, a conjuntura, e chegavam à conclusão de que era preciso avançar, mas as condições não estavam dadas; e que ele se pergunta o que fazer para que, em vez de esperar que as condições sejam dadas, elas sejam construídas. Então toda aposta dele na sua vida acadêmica, melhor dizendo na sua vida política, e sobretudo nos seus textos mais recentes, para não dizer os últimos textos porque ele continua pensando, é o que fazer para constituir novos sujeitos. Ele diz o seguinte: que, para examinar a constituição do sujeito, você precisa considerar uma dimensão subjetiva e uma dimensão objetiva. A dimensão subjetiva vai depender muito da vida de cada um de nós, da nossa história pregressa. Você nasceu muito tempo depois de mim, talvez tenha a idade da minha filha, foi uma época em que trabalhar no coletivo, trabalhar no serviço público era demonstração de incompetência, porque as pessoas que eram competentes venciam a vida no privado. Isso então estimulava o individualismo, não é? Pode ser que vocês tivessem uma experiência pessoal que os levasse para outro lado. Eu sou de uma geração de 68. Todo mundo mudou um pouco em determinados aspectos a partir de 68, então a minha história de vida pode ser diferente das suas histórias. Com isso, nós podemos ser críticos ou não. Se eu passei por uma experiência que me ponha crítico eu vou ser crítico, subjetivamente. Se talvez minha filha, ou o meu filho não passou, ele não teria essa tendência, do ponto de vista da cabeça dele, subjetivamente, a ser crítico. Mas essas pessoas estão em organizações como essas de vocês, e esse tipo de organização pode objetivamente, por uma iniciativa política institucional, desenvolver ou não uma aptidão crítica nas pessoas. E então, os indivíduos podem vir com uma atitude crítica ou não, mas vão encontrar uma organização que pode desenvolver uma aptidão crítica, sim ou não. Se uma pessoa não teve nenhuma experiência que o fizesse crítico e passa por uma organização que não desenvolva uma aptidão crítica nele, ele vai ser um sujeito passivo. Por outro lado, se o sujeito teve uma experiência de vida que o fazia ter uma atitude crítica perante a vida e vai entrar numa organização que não desenvolva uma aptidão crítica, ele vai ser uma pessoa que vai ficar retomando suas críticas o tempo todo na instituição, ele vai fazer uma oposição estéril, porque não vai conseguir construir. Ele tinha todo o potencial de desenvolver algo construtivo e a instituição não ajudou. Se você tem uma atitude que não é crítica, mas entra numa instituição que desenvolve aptidão crítica, você vai ser um funcionário diferente, mesmo sem ter tido a experiência. E aí para fechar as casinhas imaginárias do professor Mario Testa, se você tem uma atitude crítica e chega numa instituição que desenvolve uma aptidão crítica, você é potencialmente um sujeito transformador. Isso eu estou falando individualmente, mas acho que também as organizações enquanto sujeitos coletivos podem se constituir de algo que é potencial e, passando por vários processos, se torna real. Tem uns esquemas muito interessantes para a gente poder ver que não é questão de otimismo ou pessimismo, quer dizer, existem condições objetivas que impedem determinados avanços, mas isso não deve ser pretexto nem desculpa para não constituir novos sujeitos que, daqui a cinco anos, daqui a dois ou daqui a dez, vão dar passos que nós não conseguimos dar em 2016. 
Reciis: Em algumas de suas intervenções, a questão da comunicação surge não como ferramenta ou instrumento para o planejamento e a gestão em saúde, mas sobretudo como uma forma de reflexão sobre a linguagem e a cultura. Num contexto marcado por novas tecnologias de comunicação, emergem novas formas de participação e mobilização em saúde. A discussão sobre o aborto no contexto da epidemia de zika ocupou grande espaço nas redes sociais, acionando novas formas de ativismo. Por quais transformações passa a política - e, particularmente, as políticas de saúde - num contexto marcado concomitantemente por novas formas de ativismo e o recrudescimento de um conservadorismo autoritário?

Jairnilson Paim: Eu noto que essas diferentes formas de ativismo expressam e revelam a complexidade que tem a nossa sociedade contemporânea. Os conflitos maiores não se esgotam na relação capital-trabalho. Vão sendo desenvolvidas outras tantas manifestações em que o antagonismo se expressa. Eu penso que um dos pontos que, de alguma forma, a gente precisa explorar um pouco é - vou me socorrer com um autor latinoamericano e também e com uma autora do Norte - buscar certas equivalências dessas grandes relações sociais em que o conflito se estabelece e o protagonismo se coloca. Em outras palavras, como buscar uma forma em que esses diferentes jeitos de realização, esses projetos distintos de sociedade comecem a dialogar? Eu estava dando um exemplo com o movimento de 2013, quer dizer, não adianta você dizer para as feministas que a questão da reforma sanitária é mais importante do que o movimento delas; não adianta você dizer para o movimento negro ou para os indigenistas que a reforma sanitária abrange tudo, mas é preciso buscar quais são os pontos em que o antagonismo se expressa nas relações sociais entre esses diferentes espaços, e como é que se pode construir uma cadeia de equivalências que faz com que a democracia se expresse no cotidiano para a construção dessa vontade coletiva. Isso é o que o Laclau, o Ernesto Laclau, que é um argentino, e a Chantal Mouffe ${ }^{9}$ chamam de radicalização da democracia, que é uma estratégia em que as diferenças possam ser reconhecidas; trata-se de buscar uma equivalência dessas experiências, não no sentido de dominação de algo que os marxistas tanto valorizaram que era a luta entre capital e trabalho, mas significa você ter uma abertura para entender todos esses processos que a própria complexidade da sociedade está construindo e buscar formas de ligação desses movimentos num projeto mais amplo de mudança da sociedade. Suponho que esse é um ponto em que, através dos instrumentos de comunicação, a questão do aborto, a questão da epidemia de zika, todos esses movimentos que estão aparecendo hoje permitem você ter cadeias de equivalências para uma luta social mais ampla. Agora mesmo com o vírus zika, já que vocês trouxeram o exemplo do aborto, você vai ver as várias manifestações que, geralmente, eram manifestações pontuais, as feministas discutindo o aborto, mas com o cuidado de isso não justificar a eugenia, não é? Você vê os epidemiologistas trabalhando com a ideia de que é preciso combater o mosquito, mas não se pode contaminar o ambiente. Os outros - pediatras, neonatologistas e ginecologistas preocupados com a assistência pré-natal, com o parto mesmo, o que se deverá fazer para estimular precocemente as crianças, mas sempre com ações ou com pensamentos, ou com textos, discursos muito pontuais. Isso nos incomodou tanto que, no âmbito do observatório que eu coordeno de análise de política de saúde ${ }^{\mathrm{ii}}$, nós estimulamos alguns professores pesquisadores dessa temática a escreverem um documento, como um position paper, um documento de posição, tentando articular esse conjunto de questões. Então chamamos as pessoas que pesquisavam o mosquito, chamamos as pessoas que estudavam a neurologia pediátrica, a psiquiatria infantil, chamamos pessoas que trabalhavam com a questão da saúde da mulher e fizemos um documento relativamente ousado para os padrões, defendendo a questão do aborto, defendendo claramente que as mulheres precisavam ter informações para decidir se querem ou não manter a gravidez naquele período, enquanto a ciência ainda produz conhecimento. Então, eu acho que essa é uma pequena ilustração de como buscar os equivalentes em uma ação coletiva mais humanitária, respeitando a diversidade de cada um dos movimentos. Esse documento ${ }^{10}$ está no observatório, vocês podem visitar o site.

ii Trata-se do Observatório de Análise Política em Saúde (OAPS): www.analisepoliticaemsaude.org/oaps/. 
Reciis: Até que ponto os princípios do SUS ${ }^{\text {iii }}$, como universalidade, integralidade, participação, regionalização e descentralização, por exemplo, propostos pela Reforma Sanitária, conseguiram ser efetivamente cumpridos e quais são ainda pontos críticos do sistema?

Jairnilson Paim: Nós conseguimos avançar na descentralização, conseguimos avançar na participação da comunidade, que era a segunda diretriz; nós conseguimos avançar muito na integralidade, pelo menos, na Atenção Básica, que eu dou como exemplo o Saúde da Família. Se você for pensar, por exemplo, em Vigilância em Saúde, o que se conseguiu avançar em vigilância ambiental, em vigilância epidemiológica, saúde do trabalhador, vigilância sanitária - que era um caso de polícia, e hoje se respeita a experiência da Anvisa -, nós avançamos muito. Eu lembro que dentro desse aspecto, a questão da qualidade do cuidado, a segurança do paciente - que é uma das áreas de importância em que a Cláudia Travassos ${ }^{\text {iv }}$ tem investido muito -, e a questão da integralidade do cuidado dos vários níveis, eu acho que são pontos que vão ressoar na regionalização. A regionalização é um dos grandes nós. Os grupos que estão estudando a regionalização têm, muitas vezes, o discurso da solidariedade, mas não existe solidariedade entre instâncias de governo, entre instâncias estatais, o que temos é uma luta política. Enquanto o componente da análise política, da análise estratégica não estiver presente nos que estão coordenando ou estão articulando os esforços da regionalização, a gente não vai encontrar saída. Porque não é um desenho de redes que vai dar conta. Quer dizer, quais são os fatos que podem ser construídos com a situação que nós temos hoje? Eu suspeito que algumas teses de doutorado que têm estudado a regionalização, pelo menos eu conheço uma do Ceará, conheço outra do Mato Grosso, que foi um dos lugares que quase se antecipou na questão da regionalização possam contribuir para esclarecer os obstáculos para a regionalização. Nós não fomos treinados para contratualização, nós fomos qualificados para trabalhar com determinados valores do interesse público e não sabemos como é que se negocia com quem está olhando somente para o lucro. Porque, na medida em que toda a parte da atenção especializada vai depender de compras do setor privado, o sistema público se torna refém, o discurso da racionalidade ou o discurso do bem comum não sensibiliza quem está do outro lado. Ou você trabalha com determinados cálculos que os empresários fazem acerca disso, ou você dança. Então, acho que inclusive tem todo um conhecimento do qual talvez os economistas ou os administradores disponham, que é de como tratar com o outro lado do balcão; nós, da chamada saúde pública ou dos serviços públicos de saúde, não fomos qualificados para isso. Então eu imagino que um grande desafio para a regionalização, quer dizer, para a construção de pactos e para a negociação dos vários níveis de atenção, é você ter uma lógica de negociação que está muito mais do lado de quem negocia economicamente do que quem negocia em termos de perfis epidemiológicos ou de protocolos, ou de padrões de qualidade. Isso nós não ensinamos na nossa pós-graduação: como é que se lida com empresários? Muitos de nós que passamos a ser gestores intuímos que devemos ficar com um olho no padre, um olho na missa, sabendo que aquele sujeito pode estar querendo te corromper, ou não, mas isso é uma coisa muito intuitiva. Tem um livro chamado 'O que a Harvard não ensina' ${ }^{\text {'1 }}$. Então eu suspeito que tem uma coisa que talvez a Fiocruz e a Ufba não ensinem: como é que se deve lidar com empresários que vão lá para te corromper? Como é que se faz isso? Como é que você administra, como é que você vai buscar a compra de serviços de saúde, porque você é refém dele, mantendo o interesse público como dominante ou, pelo menos, o primado do interesse público? Então, penso que esses são pontos que estão na regionalização e que muitas vezes não têm sido problematizados, como se a regionalização fosse apenas a gente ter uma região com os deseinhos, e fulano vai para aqui, vai para acolá, e cria um comitê qualquer, um comitê que não tem poder e não pode pactuar. Há coisas que são da política, do pensamento do agir estratégico, que me parece que são fundamentais para nortear esse grande desafio que é a regionalização.

iii Mais sobre o Sistema Único de Saúde, ver 'O que é o SUS', de Jairnilson Paim, e-book interativo da Editora Fiocruz: http:// portal.fiocruz.br/pt-br/content/o-que-e-o-sus-e-book-interativo.

iv Atualmente pesquisadora da Fiocruz e consultora do Proqualis (Qualidade no cuidado e segurança do paciente), Travassos trabalha com pesquisas voltadas para a saúde coletiva. 
Reciis: Como a comunidade científica deve lidar com o impacto das novas tecnologias, no que se refere ao relacionamento com o cidadão: como lidar com o Dr. Google? Como administrar o espraiamento 'a jato' de boatos? Como lidar com um possível 'bypass', já ocorrido, no caso da Fosfoetanolamina, e quais as lições que esse episódio nos reserva, uma vez que quando a comunidade científica se manifesta 'em peso' e não é ouvida, o que nos falta? O que devemos questionar e aprender com esse episódio?

Jairnilson Paim: O Dr. Google é muito problemático. Tem muitos efeitos colaterais, como nós diríamos em medicina. Mas o Dr. Google tem um aspecto positivo que eu queria destacar. Ele problematiza a soberba dos médicos, não é?! Questiona a arrogância de muitos de nós, profissionais de saúde. Eu acho que quando a pessoa chega numa consulta ou numa reunião, e que antes viu o Dr. Google e por isso tem informações, eu acho que já chega com o poder que nós chamaríamos de poder técnico, poder de informação, que dá para dialogar com o poder de um profissional de saúde. Então eu vejo, com as ressalvas que eu fiz antes, a importância do Dr. Google, de você ter acesso às informações. Eu não sei como é que se poderia administrá-lo melhor para evitar a proliferação de boatos etc. Mas acho que quando você começa a divulgar informações que têm fontes mais confiáveis, como no PenseSUS, no Canal Saúde ou num Observatório, por exemplo, eu acho que as pessoas vão ser mais seletivas, e vão dar credibilidade a essa ou àquela fonte. Essa experiência é recente no Brasil.

Em relação ao caso da Fosfoetanolamina, eu estava lendo uma entrevista do Jarbas Barbosav ${ }^{v}$, ele dizia que o problema maior não é a desmoralização da Anvisa. A Anvisa de alguma forma, ele não diz isso, mas eu quero dizer, é uma instituição respeitada no Brasil, até pela mídia. O maior problema dessa ação é que fragiliza o Brasil enquanto nação perante o mundo, não é. Quer dizer, é uma medida calamitosa, esse ponto eu acho que vai ter uma repercussão. Não adianta a gente imaginar que nós como pesquisadores ou professores tenhamos tanto poder, como o Congresso Nacional tinha, e como teria a Presidente da República para fazer um veto. Ela examinou, estava vivendo uma conjuntura especial. Ela podia dar o veto e o veto ser derrubado depois, não é? Mas eu acho que nesse caso foi traumático, foi uma excrescência isso que o Congresso Nacional fez. Resultante da iniciativa de um líder, lamentavelmente de um partido que se chama Partido da Mulher Brasileira, que é um homem, que parece que é o único deputado desse partido, e que daí entra numa espiral, em que a Câmara aceita, o Senado praticamente apoia integralmente e só restaria à Presidente da República fazer o veto. Isso é um escândalo. Então, eu acho que isso vai deixar marcas dentro da sociedade brasileira, que a levará a ter mais cuidado. Eu acho que a própria repercussão que esse fato vai criar internacionalmente vai fazer com que muitas dessas medidas futuras possam ser pensadas duas vezes antes de serem adotadas. Constato que isso foi um péssimo exemplo que o Brasil deu quando justamente estava criando um saber e uma instituição forte para regular a pesquisa médica e a utilização dos produtos dessas pesquisas na rede de serviços de saúde. Lamentável! Mas os pontos negativos também depois podem virar contribuições positivas. Eu diria, como Mario Testa, que é o uso positivo das contradições e conflitos.

v Entrevista concedida à Folha de S.Paulo, publicada em $1^{\circ}$ de maio de 2016. Disponível em: http://www1.folha.uol.com.br/ cotidiano/2016/05/1766592-caso-como-o-da-pilula-do-cancer-prejudica-o-pais-diz-diretor-da-anvisa.shtml 


\section{Reciis: O momento atual é de pessimismo?}

Jairnilson Paim: Na saúde, tivemos vários momentos muito difíceis, mas conseguimos dar a volta por cima. Eu gosto muito de colocar isso porque não é uma esperança, como diria Paulo Freire, de quem cruza os braços e espera, não é. Ele dizia que é uma esperança diferente: "movo-me na esperança enquanto luto e, se luto com esperança, espero" ${ }^{12}$. Incrível o que o Paulo Freire ensinava para a gente, não é? Então é esse o desafio, as contradições estão aí. Uma sociedade capitalista cada vez mais vai engendrando novas situações, novas contradições. Não é linear. Não adianta você fazer linha do tempo, porque em um determinado momento há vários fenômenos ocorrendo naquela mesma situação. A forma arquitetônica daquilo ali não pode ser nunca uma linha, não é. É tridimensional, é multidimensional, então eu acho que determinadas ferramentas teóricas, que não são quaisquer ferramentas, podem nos ajudar. Não é que tenha esperança, nem aquela coisa do otimismo da prática versus o pessimismo da razão. Isso faz parte da natureza da história da humanidade e também da nossa história pessoal.

\section{Referências}

1. Gramsci A. Cadernos do cárcere. Vol 5. Rio de Janeiro: Civilização Brasileira; 2002

2. Paim, JS. Reforma Sanitária Brasileira: contribuição para a compreensão e crítica. Salvador: Edufba; Rio de Janeiro: Editora Fiocruz; 2008.

3. Heller, A. Teoría de las necesidades en Marx. Trad. J. F. Yvars. Barcelona: Ediciones Península; 1986.

4. Canguilhem, G. O normal e o patológico. 6a ed. São Paulo: Forense Universitária; 2009

5. Paim, JS. O futuro do SUS. Cad. Saúde Pública [Internet]. 2012 Abr; 28(4):612-612. [citado 2016 Jun 05]. Disponível em: http://www.scielo.br/scielo.php?script=sci arttext\&pid=S0102311X2012000400001\&lng=pt

6. Oliveira VC. A comunicação midiática e o Sistema Único de Saúde. Interface (Botucatu) [Internet]. 2000 Ago [citado 2016 Jun 06] ; 4(7):71-80. Disponível em: http://www.scielo.br/scielo.php?script=sci arttext\&pid $=$ S1414-32832000000200006\&lng $=p t$

7. Paim, JS. A Constituição Cidadã e os 25 anos do Sistema Único de Saúde (SUS). Cad. Saúde Pública [Internet]. 2013 Out [citado 2016 Jun 05] ; 29(10):1927-1936. Disponível em: http://www.scielo.br/ scielo.php?script=sci arttext\&pid=S0102-311X2013001000003\&lng=pt

8. Testa M, Paim JS. Memoria e Historia: diálogo entre Mario Testa y Jairnilson Silva Paim. Salud Colectiva. 2010;6(2):211-227.

9. Laclau E, Mouffe C. Hegemony and Socialist Estrategy: Towards a radical democratic politics. Londres, Verso; 1985.

10. Santos DN, Aquino EML, Menezes GMS, Paim JS, Silva LMV, Souza LEPF et al. Documento de posição sobre a tríplice epidemia de Zika-Dengue-Chikungunya [Internet]. 2016. [citado 05 maio 2016] Disponível em: http://analisepoliticaemsaude.org/up/oaps/noticias/pdf/1460471915570d086b9f2be.pdf

11. McComarck, MH. O que não se ensina em Harvard Business School. Rio de Janeiro: Best Seller; 1985.

12. Freire, P. Pedagogia do oprimido. São Paulo: Paz e Terra; 1974. 